\title{
Comparative Gastro-Protective Effects of Nigella sativa (Kalojira) and Omeprazole against Aspirin Induced Gastric Ulcer in Albino Rats
}

\author{
Nashid Sultana ${ }^{1}$, Md. Ismail Khan ${ }^{2}$, Nasim Ahmed ${ }^{3}$, Md. Shakil Akhter ${ }^{4}$, Azmary Momtaz
}

\begin{abstract}
Background: Nigella sativa seeds have been in use as a natural remedy for over thousands of years in various parts of the world. These seeds are reported to have beneficial effects almost on every system of the body. Objective: To evaluate the gastro-protective effect of Nigella sativa on aspirin induced gastric ulcer with comparison to omeprazole. Materials and method: This experimental study was carried out in the department of Pharmacology and Therapeutics, Dhaka Medical College, Dhaka, Bangladesh in collaboration with the department of Pathology, Delta Medical College, Dhaka, Bangladesh. A total number of 30 healthy albino rats were used in this study. The experiment was divided into 2 parts: Experiment-1 and Experiment-2. Experiment-1 comprised of 12 rats: Group-A and Group-B having 6 rats in each group. Ulcer was produced by administration of aqueous suspension of aspirin $(200 \mathrm{mg} / \mathrm{kg}$ body wt) in Group-B where Group-A served as control and was provided with normal saline $(2 \mathrm{ml} / \mathrm{kg}$ body $w \mathrm{t})$. All the rats were sacrificed after $4 \mathrm{hrs}$ to confirm gastric ulcer by histopathology. Experiment-2 comprised of 18 rats: Group-C, Group-D and Group-E having 6 rats in each group. Group-C served as disease control group and provided with normal saline $(2 \mathrm{ml} / \mathrm{kg}$ body wt). Group-D was provided with alcoholic extract of Nigella sativa (150 mg/kg body wt) and Group-E was provided with omeprazole suspension $(20 \mathrm{mg} / \mathrm{kg}$ body wt). After 8 days of treatment, animals were fasted for 24 hrs. Then aqueous suspension of aspirin (200 mg/kg body wt) was administered and after 4 hrs all rats were sacrificed. Gross and microscopic examinations were performed to evaluate the results. Results: Aspirin caused marked gastric damage in negative control group which was prevented in omeprazole suspension and Nigella sativa extract treated groups significantly. The protective effect was maximum with omeprazole followed by alcoholic extract of Nigella sativa. Conclusion: Alcoholic extract of Nigella sativa showed significant protection against aspirin induced gastric ulcer in rats as compared to omeprazole.
\end{abstract}

Keywords: Nigella sativa; omeprazole; aspirin; gastric ulcer.

Delta Med Col J. Jul 2016;4(2):61-66

\section{Introduction}

Peptic ulcer disease is believed to be due to an imbalance between aggressive and protective factors in the stomach. ${ }^{1}$ Drug treatment of peptic ulcer is targeted at either counteracting aggressive

1. Assistant Professor, Department of Pharmacology \& Therapeutics, Delta Medical College, Dhaka, Bangladesh.

2. Professor and Head, Department of Pharmacology \& Therapeutics, Dhaka Medical College, Dhaka, Bangladesh.

3. Professor and Head, Department of Pathology, Delta Medical College, Dhaka, Bangladesh.

4. Associate Professor, Department of Pharmacology and Therapeutics, Bangladesh Medical College, Dhaka, Bangladesh.

5. Assistant Professor, Department of Pharmacology \& Therapeutics, Delta Medical College, Dhaka, Bangladesh.

Correspondence: Dr. Nashid Sultana. e-mail: nashidrumana@gmail.com 
factors (acid, pepsin, platelet aggravating factor, leukotrines, etc.) or stimulating the mucosal defences (mucus, bicarbonate, normal blood flow, prostaglandins, nitric oxide). ${ }^{2}$ The goals of treating peptic ulcer disease are to relieve pain, heal the ulcer and prevent ulcer recurrence. Currently, there is no cost effective treatment that meets all these goals. Hence efforts are on to find a suitable treatment from natural product sources. A large percentage of world population, especially in the developing countries, relies on natural remedies to treat a variety of diseases. So a large number of spices and herbs have been evaluated by various researchers for their anti ulcer effects. ${ }^{3}$

Nigella sativa (kalojira) seeds have been in use as a natural remedy for over 4000 years in various parts of the world. These seeds are reported to benefit almost every system of the body. ${ }^{4-7}$ It is reported to have various pharmacological activities like anti diabetic, analgesic, anti inflammatory, anti oxidant, anti tumour, wound healing and very few reports on gastro-protective activity against NSAIDs induced gastric damage. ${ }^{8-13}$

Although, to prevent gastric damage, many of the drugs are available like proton pump inhibitors, $\mathrm{H}_{2}$ blockers but they also have adverse effects. Newer drugs which have minimal adverse effects with maximum benefit are continuously searched worldwide to prevent the gastric damages induced by NSAIDs. So, in this regard study was planned to evaluate protective effects of Nigella sativa against aspirin induced gastric damages in experimental rats.

\section{Materials and method}

This experimental study was conducted in the department of Pharmacology \& Therapeutics, Dhaka Medical College, Dhaka, Bangladesh in collaboration with the department of Pathology, Delta Medical College, Dhaka, Bangladesh from January 2010 to December 2010.
Experimental animals: The experiment was carried out on a total number of 30 healthy albino rats. The rats were aged between 8-10 weeks of both sex and weighing between 150-175 gm. They were kept in medium sized metallic cages in animal house of Pharmacology department at Dhaka Medical College, Dhaka, Bangladesh. They were allowed to live at room temperature, fed on standard pellets of rat food and allowed to drink tap water.

Plant material: Alcoholic extract of Nigella sativa was made from kalojira which was bought from local market of Dhaka, Bangladesh.

\section{Drugs and chemicals}

i) Aspirin was bought from local medicine shop, Dhaka, Bangladesh.

ii) Omeprazole sachet was bought from local medicine shop, Dhaka, Bangladesh and diluted with water to make suspension.

iii) $0.9 \%$ Sodium Chloride (normal saline) and distilled water were supplied by the department of Pharmacology of Dhaka Medical College, Dhaka, Bangladesh.

Preparation of plant extract: 1000 gm of Nigella sativa (kalojira) was purchased from the local market. The seeds were dried and crushed into coarse powder which was macerated with alcohol $(99 \% \mathrm{v} / \mathrm{v})$ using soxhlet apparatus. The extract was evaporated by rotator evaporator at an optimum temperature of $40-50^{\circ} \mathrm{C}$ under vacuum. The extractive value $(\mathrm{v} / \mathrm{v})$ of alcoholic dry extract was $4.25 \%$.

Experiment design: The experiment was divided into 2 parts: Experiment-1 and Experiment-2.

\section{Experiment-1}

It comprised of 12 rats which were divided into 2 groups each having 6 rats. Groups were labelled as Group-A and Group-B. 
Group-A: This group served as control group and they were provided with normal saline $(2 \mathrm{ml} / \mathrm{kg}$ body wt) orally by gastric tube.

Group-B: This group was provided with aqueous suspension of aspirin (200 mg/kg body wt) orally by gastric tube. After $4 \mathrm{hrs}$ all rats were sacrificed by an overdose of diethyl ether and stomach was collected for gross and histopathological study. Experiment on these groups was carried out to evaluate the effect of aqueous suspension of aspirin in rats.

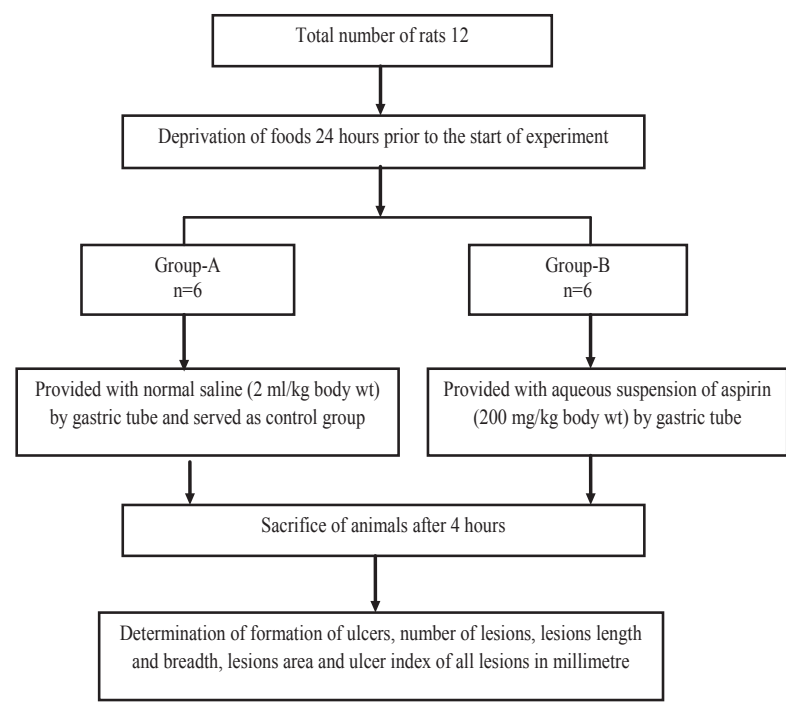

Fig 1: Flow chart of Experiment-1

\section{Experiment-2}

It comprised of 18 rats. They were divided into 3 groups each containing 6 rats labelled as Group-C, Group-D and Group-E.

Group-C: This group served as disease control group and were provided with normal saline (2 $\mathrm{ml} / \mathrm{kg}$ body wt) orally by gastric tube for 8 days.

Group-D: They were provided with alcoholic extract of Nigella sativa $(150 \mathrm{mg} / \mathrm{kg}$ body wt) orally by gastric tube for 8 days.

Group-E: They were provided with omeprazole suspension (20 mg/kg body wt) orally by gastric tube for 8 days.
After 8 days of treatment, animals were fasted for $24 \mathrm{hrs}$. Then administration of aqueous suspension of aspirin ( $200 \mathrm{mg} / \mathrm{kg}$ body wt) by gastric tube and after 4 hrs, all rats were sacrificed by an overdose of diethyl ether and stomach was collected for gross and histological study. Experiment in these groups was carried out to evaluate the gastroprotective effect of alcoholic extract of Nigella sativa on aspirin induced gastric ulcer in rats as compared to omeprazole.

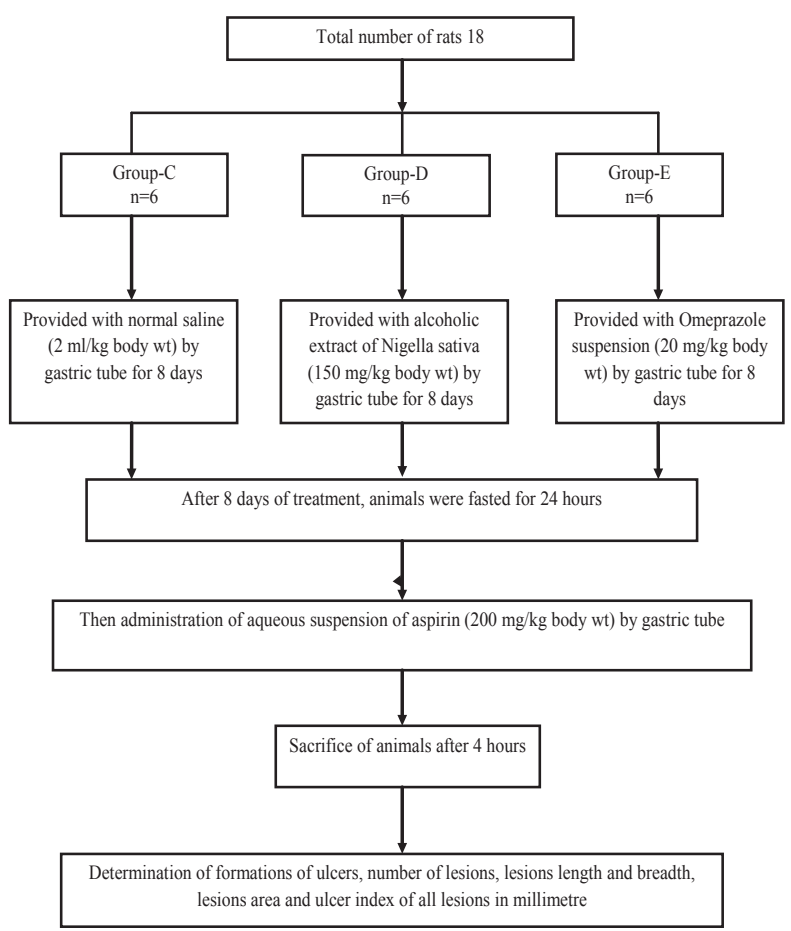

Fig 2: Flow chart of Experiment-2

\section{Morphological parameter studied}

i) Number of lesion (Mean \pm SD) per rat in each group.

ii) Individual lesion length and breadth in $\mathrm{mm}$ (Mean \pm SD) for each group.

iii) Individual lesion area (length $\times$ breadth) in square $\mathrm{mm}(\mathrm{Mean} \pm \mathrm{SD})$ for each group.

iv) Mean ulcer index in $\mathrm{mm}$ for each group.

\section{Ulcer index}

Stomach was cut along the greater curvature, 
washed and placed on a card board and ulcer index was counted from the glandular portion. Each lesion was measured along the greatest length and evaluated singly according to their dimensions and severity. Ulcer index $=10 / x ; \quad(x=$ area of glandular portion of stomach / area of ulceration in $\mathrm{mm}^{2}$ scale). ${ }^{14}$

Statistical analysis: All relevant information for each rat was recorded in a predesigned data collection sheet. Collected data were screened and compiled. All data were recorded in tabulated form and the results were expressed as Mean \pm SD. Unpaired t-test was done to find then significant difference between groups.

\section{Results}

Table I shows the effect of aqueous suspension of aspirin in rats. Group-A had no lesion in the stomach but in Group-B there were ulcers of different dimensions. Thus, aqueous suspension of aspirin was shown to have strong ulcer producing effect in rats.

Table I: Effect of Aspirin on mean lesion length, lesion breadth, lesion area and lesion index in each group

\begin{tabular}{lcc}
\hline Parameters & $\begin{array}{c}\text { Group-A } \\
(\mathbf{n}=\mathbf{6}) \\
\text { Mean } \pm \text { SD }\end{array}$ & $\begin{array}{c}\text { Group-B } \\
(\mathbf{n}=\mathbf{6}) \\
\text { Mean } \pm \text { SD }\end{array}$ \\
\hline Mean lesion length in $\mathrm{mm}$ & 0 & $6.52 \pm 3.80$ \\
Mean lesion breadth in $\mathrm{mm}$ & 0 & $1.63 \pm 1.35$ \\
Mean lesion area in $\mathrm{mm}^{2}$ & 0 & $13.58 \pm 15.91$ \\
Mean lesion index $\mathrm{mm}^{2}$ & 0 & $31.50 \pm 9.61$ \\
\hline
\end{tabular}

Group-A was served as control group and was provided with normal saline ( $2 \mathrm{ml} / \mathrm{kg}$ body wt) by gastric tube.

Group-B was provided with aqueous suspension of aspirin (200 mg/kg body wt) by gastric tube.

Table II shows the comparative gastro-protective effects of Nigella sativa and omeprazolein rats.
Table II: Effects of alcoholic extract of Nigella sativa and omeprazole on mean lesion length, lesion breadth, lesion area and lesion index in each group

\begin{tabular}{lccc}
\hline Parameters & $\begin{array}{c}\text { Group-C } \\
(\mathbf{n}=\mathbf{6}) \\
\text { Mean } \pm \text { SD }\end{array}$ & $\begin{array}{c}\text { Group-D } \\
(\mathbf{n}=6) \\
\text { Mean } \pm \text { SD }\end{array}$ & $\begin{array}{c}\text { Group-E } \\
(\mathbf{n}=6) \\
\text { Mean } \pm \text { SD }\end{array}$ \\
\hline Mean lesion length in $\mathrm{mm}$ & $6.75 \pm 3.71$ & $3.48 \pm 2.25$ & $2.38 \pm 1.84$ \\
Mean lesion breadth in $\mathrm{mm}$ & $1.63 \pm 1.29$ & $0.77 \pm 0.48$ & $0.64 \pm 0.66$ \\
Mean lesion area in $\mathrm{mm}^{2}$ & $13.66 \pm 15.14$ & $1.30 \pm 3.55$ & $2.58 \pm 5.26$ \\
Mean lesion index $\mathrm{mm}^{2}$ & $36.00 \pm 11.08$ & $14.51 \pm 2.47$ & $9.91 \pm 2.82$ \\
\hline
\end{tabular}

Group-C was disease control group and they were provided with normal saline $(2 \mathrm{ml} / \mathrm{kg}$ body $\mathrm{wt}$ ) for 8 days.

Group-D was provided with alcoholic extract of Nigella sativa ( $150 \mathrm{mg} / \mathrm{kg}$ body $\mathrm{wt}$ ) for 8 days.

Group-E was provided with omeprazole suspension ( $20 \mathrm{mg} / \mathrm{kg}$ body wt) for 8 days. After 8 days of treatment, animals were fasted for $24 \mathrm{hrs,}$ then administration of aqueous suspension of aspirin ( $200 \mathrm{mg} / \mathrm{kg}$ body wt) by gastric tube.

\section{Comparing Group-D with Group-C (control)}

There was a significant reduction in ulcer length, ulcer breadth, ulcer area and ulcer index seen in Group-D which waspre-treated with alcoholic extract of Nigella sativa. Resultswere highly significant $(\mathrm{p}<0.001)$. Thus, alcoholic extract of Nigella sativa showed to have a significant gastro-protective effect in rats.

\section{Comparing Group-D with Group-E}

Reduction of ulcer length, ulcer breadth, ulcer area and ulcer index was not significant between the groups $(p>0.05)$. Thus, Nigella sativa showed to have equal efficacy as omeprazole in gastro-protection in experimental rats.

\section{Discussion}

Uncontrolled acid secretion and ulceration of gastric mucosa due to several reasons is a serious problem to human health all over the world. Many 
natural products and modern synthetic agents have been used to treat peptic ulcer disease but so far a complete cure has not been discovered and exploration of new anti ulcer drug has remained a field of active research. ${ }^{15}$

In an effort to further search, the present study is undertaken to search the curative and safe agents for the treatment of peptic ulcer in our indigenous medicinal plants. The gastro-protective efficacy of Nigella sativa extract is determined in albino rats having aspirin induced ulcers. The aspirin model has already been utilized for screening the new compounds for their anti ulcer effects. Use of this model for the same purpose has been employed for several workers including Akhtar\& Munir ${ }^{16}$ and Eddlestonet al. ${ }^{17}$

The present study was carried out to evaluate the gastro-protective effect of alcoholic extract of Nigella sativa in albino rats. In this study, aqueous suspension of aspirin was used to induce gastric ulcer in rats. The dose androutes of administration of aspirin were selected from Rajkapoor\& Anandan. ${ }^{18}$ Oral administration of single dose of aqueous suspension of aspirin $(200 \mathrm{mg} / \mathrm{kg}$ body wt) produced significant gastric mucosal damage in rats. Similar observations were reported by number of researchers. ${ }^{19}$ It was concluded that aqueous suspension of aspirin is a potent ulcerogenic agent in rats. The protective role of Nigella sativa extract was demonstrated in prevention of gastric ulcer developed in aspirin treated rats. The dose and duration of alcoholic extract of Nigella sativa were selected from Bruits \& Bucar. $^{10}$

In this study, there was remarkable and significant change in the mean value of ulcer number, ulcer length, ulcer breadth, ulcer area and ulcer index in rats treated with alcoholic extract of Nigella sativa and omeprazole as compared with rats provided with normal saline. This was consistent with the previously reported work by Ghannadiet al. ${ }^{20}$
Therefore, it can be concluded that Nigella sativa extract has role in prevention of gastric ulcer developed in aspirin treated rats. Finally, the experimental and histological findings provided support for the gastro-protective effect of alcoholic extract of Nigella sativa in aspirin induced gastric damage in rats. A similar histological finding was observed in an experiment performed by Al-Mofleh \& Haider. ${ }^{21}$ Pretreatment with Nigella sativa and omeprazole prevented histopathological changes such as congestion, haemorrhage, oedema, inflammatory and dysplastic changes. The findings of this study were in well agreement with various data reporting that alcoholic extract of Nigella sativa reduced the number of lesions, lesions length, lesions breadth, lesions area and ulcer index in rats. ${ }^{22}$ The current study demonstrated that Nigella sativa has gastro-protective activity as well as omeprazole.

\section{Conclusion}

Nigella sativa is almost equally effective in healing of gastric ulcer as is omeprazole. The observations and results of this study provided a rationale for the use of Nigella sativa in the development of a new drug for the therapy of gastric ulcer disease. In Bangladesh, Nigella sativa is not used in gastric ulcer therapy in routine practice. On the basis of present study, it is suggested that further broad spectrum studies as well as clinical trials should be conducted before the use of this product as routine medicine.

\section{References}

1. Alkofahi A, Atta AH. Pharmacological Screening of the Antiulcerogenic Effects of Some Jordanian Medicinal Plants in Rats. J Ethnopharmacol. 1999;65:341-45.

2. Peskar BM, Maricic N. Role of Prostaglandins in Gastroprotection. Dig Dis Sci. 1998;43:S23. 
3. Al-Mofleh IA, Alhaider AA, Mossa JS, Al-Sohaibani MO, Rafatullah S, Qureshi S. Protection of Gastric Mucosal Damage by Coriandrum sativum L. Pretreatment in Wistar Albino Rats. Environ Toxicol Pharmacol. 2006;22:64-69.

4. Akhondian J, Parsa A, Rakhshande H. The Effect of Nigella sativa L on Intractable Paediatric Seizures. Med Sci Monit. 2007;13:555-59.

5. Kalus U, Pruss A, Bystron J, Jurecka M, Smekalova A, Lichius JJ, et al. Effect of Nigella sativa on Subjective Feeling in Patients with Allergic Diseases. Phytother Res. 2003;17:1209-14.

6. Salih B, Sipahi T, Donmez EO. Ancient Nigella sativa Seeds from Boyali Hoyuk in North-Central Turkey. J Ethnopharmacol. 2009;124:416-20.

7. Farah KM, Atoji Y, Shimizu Y, Shiina T, Nikami H, Takwwaki T. Mechanisms of the Hypoglycaemic and Immunopotentiating Effects of Nigella sativa L. Oil in Streptozotocin- Induced Diabetic Hamsters. Res Vet Sci. 2004;77:123-29.

8. Meral I, Yener Z, Ozbek H,Ustun R. Effects of Nigella sativa L. on Serum Concentrations of Thyroid Hormones, Thyroid Stimulating Hormone and Glucose in Alloxan Induced Diabetic Rabbits. Irish Veterinary Journal. 2003;56:462-64.

9. El-Gazzar M, El Mezayen R, Marecki JC, Nicolls MR, Canastar A, Dreskin SC. Anti-inflammatory Effect of Thymoquinone in a Mouse Model of Allergic Lung Inflammation. International Immunopharmacology. 2006;6:1135-42.

10. Bruits M, Bucar F. Antioxidant Activity of Nigella sativa Essential Oil. Phytotherapy Research. 2000; 14:323-28.

11. Worthen DR, Ghosheh OA, Crooks PA. The in Vitro Anti Tumour Activity of Some Crude and Purified Components of Black Seed, Nigella sativa L. Anticancer Research. 1998;18:1527-32.

12. Yaman I, Dirmus AS, Ceribasi S, Yaman M. Effects of Nigella sativa and Silver Sulfadiazine on Burn Wound Healing in Rats. Veterinary Medicina. 2010;55:619-24.
13. El-Abhar HS, Abdallah DM, Saleh S. Gastro Protective Activity of Nigella sativa Oil and Its Constituent, Thymoquinone, against Gastric Mucosal Injury Induced by Ischemia/Reperfusion in Rats. Journal of Ethnopharmacology. 2003;84: $251-58$.

14. Ganguly AK and Bhatnagar OP. Effects of Bilateral Adrenalectomy on the Production of Resistant Ulcer in the Stomach of Albino Rats. Can J Physiol Pharmacol. 1973;51:748-50.

15. Amir-Ali H. The Message of the Qur'an, Presented in Perspective. Rutland, Vermont and Tokyo: Charles E. Tuttle; 1974.

16. Akhtar MS, Munir M. Evaluation of the Gastric Antiulcerogenic Effects of Solanum nigrum, Brassica oleracea and Ocimum basilicum in Rats. J Ethnopharmacol. 1989;27:163-76.

17. Eddleston JMPR, Holland J, Tooth JA, Vohra A, Doran BH. Prospective Endoscopic Study of Stress Erosions and Ulcers in Critically Ill Adult Patients Treated with Either Sucralfate or Placebo. Crit Care Med. 1994;22:1949-54.

18. Rajkapoor BR, Anandan B, Jayakar. Anti Ulcer Effect of Nigella sativa Linn against Gastric Ulcer in Rats. Int J Immunopharmacol. 2002;82:177-79.

19. Wang Z, Hasegawa J. Protective Effects of Ginger against Aspirin Induced Gastric Ulcers in Rats. J Etnopharmacol. 2010;22:729-40.

20. Ghannadi A, Hajhashemi V, Jafarabadi H. An Investigation of the Analgesic and Anti Inflammatory Effect of Nigella sativa Seed Polyphenols. J Med Food. 2005;8:488-93.

21. Al-Mofleh IA, Haider A. Gastro-Protective Effect of an Aqueous Suspension of Black Cumin (Nigella sativa) on Necrotizing Agents Induced Gastric Injury in Experimental Animals. J Gastroenterol. 2008;14:128-34.

22. Peter C, Konturek, Brozozowask T. Effect of Helicobacter Pylori or Delay in Ulcer Healing Induced by Aspirin in Rats. J Ethnopharmacol. 2000;70:1-17. 